\title{
Family Perceptions of Participating in a Structured Summer Kindergarten Transition Program
}

\author{
Christopher Merideth ${ }^{1}$ (D) Beth Cavanaugh ${ }^{1} \cdot$ Sue Romas $^{1} \cdot$ Nicole Ralston $^{1} \cdot$ Eva $^{\text {Arias }}{ }^{2} \cdot$ Beth Tarasawa $^{2}$. \\ Jacqueline Waggoner ${ }^{1}$
}

Accepted: 28 August 2021 / Published online: 21 September 2021

(c) The Author(s), under exclusive licence to Springer Nature B.V. 2021

\begin{abstract}
Many school districts provide one-time transition events to help students prepare for the rigors of kindergarten; yet, research shows families desire additional information and opportunities to help their children thrive once school begins. Researchers for this study interviewed 39 parents whose children participated in a three-week structured kindergarten transition program designed to promote parental involvement in school, reduce students' chronic absenteeism, and increase children's readiness for kindergarten. All interviewees expressed that participating in the program yielded benefits for themselves and their children. Respondents shared that meeting education staff members early during the summer, familiarizing themselves with the layout and routines of their schools, and building stronger social connections with other families were of particular value in helping them prepare for the start of kindergarten. Similarly, understanding kindergarten expectations more thoroughly and acquiring tools to support their children at home were deemed especially beneficial for those families who had not previously participated in preschool or other structured school opportunities. In addition to positive feedback, participants proposed various ways that adjusting the program could better meet the needs of all stakeholders. Suggestions included increasing the length of the student sessions, improving communication between district and families, re-structuring the parent information sessions to be more conducive to working families, and staffing the program with more individuals who would stay on as teachers during the transition from summer to fall. Parent suggestions from this study were synthesized into multiple implications for practice and substantiated by current relevant literature.
\end{abstract}

Keywords Kindergarten $\cdot$ Transition $\cdot$ School readiness $\cdot$ Family perceptions $\cdot$ Preschool $\cdot$ Case study

Christopher Merideth

merideth15@up.edu

Beth Cavanaugh

cavanaub22@up.edu

Sue Romas

romass22@up.edu

Nicole Ralston

ralston@up.edu

Eva Arias

eva.arias@nwea.org

Beth Tarasawa

beth.tarasawa@nwea.org

Jacqueline Waggoner

waggoner@up.edu

1 School of Education, University of Portland, Portland, OR, USA

2 NWEA, Portland, OR, USA
Throughout the years, the purpose of kindergarten in America has shifted. Today, kindergarteners are expected to acquire a range of academic and social-emotional skills that serve as the foundation for a long career of educational achievement (Assel et al., 2007). Increasingly, children in kindergarten have come under scrutiny, as educational research demonstrates that acquiring literacy and other learning competencies is often a predictor of future academic success (Morgan et al., 2016; Morris et al., 2003). Children at this stage are also monitored for school readiness behaviors, such as the ability to sustain attention during academic content, as these proficiencies have also been strongly associated with long-term educational attainment (Claessens et al., 2009). Never before has the pressure on kindergarteners to perform been greater (Barbour, 2010; White, 2020).

This shift in the goal of kindergarten is also experienced by parents and caregivers (McGettigan \& Gray, 2012). In the past, kindergarten may have been primarily a time for 
socialization and creative exploration; but, today children are expected to keep pace with rigorous school routines. Kindergarten students are expected to acquire mastery of a complex set of standards, leading some schools to use rigorous diagnostic assessments as early as the first week of school (Hilbert \& Eis, 2014; Jeon et al., 2010; White, 2020). The contrast between what parents may expect based on their own kindergarten experience and the realities of today's kindergarten can be challenging to reconcile (Assel et al., 2007; Bassok et al., 2016).

Preparing for the new challenges associated with kindergarten has made attending preschool a highly recommended activity (Brooks-Gunn et al., 2013; Isaacs, 2012; Kang et al., 2017). The positive impacts of structured early childhood opportunities like preschool have been extensively studied across multiple states by the National Center for Early Development and Learning, a program funded by the U.S. Department of Education (Pianta \& Cox, 1999; Pianta et al., 2001). Research from this work and similar studies shows that children who attend preschool programs acclimate to school quickly once kindergarten begins (Atchison \& Pompelia, 2018; Ferguson \& Wood, 2005; Pianta et al., 2001). Some of the benefits of preschool attendance include greater opportunities for children from lower socioeconomic backgrounds to succeed (Ansari \& Lopez, 2015; Knudsen et al., 2006) and an overall reduction in special education placements (Pals \& Jameson, 2015). In response to these findings, cities and school districts across the nation have expanded investments in preschool (Dockett \& Perry, 2001; Meloy et al., 2019).

Despite these investments and benefits, only $54 \%$ of families in the United States access full-day preschools (National Center for Education Statistics, 2020). Moreover, research from the Brookings Institution (Isaacs, 2012) found large school readiness gaps correlated to family socioeconomic status. Though research has shown that attending preschool provides an important opportunity for young children to succeed, preschool alone may not meet the needs of all families (Bassok et al., 2018; Christakis, 2016; Dail et al., 2008). Indeed, families need additional information, assistance, and opportunities to ease their children's transition to kindergarten (Ansari et al., 2018; Kang et al., 2017; Wildenger \& McIntyre, 2011).

In an effort to address these needs, most school districts offer single-day kindergarten transition events before the start of school, such as school visits, orientation nights, and family outreach "round ups" (Atchison \& Pompelia, 2018; LoCasale-Crouch et al., 2008). While participating in these one-time events has been shown to lead to more successful social adjustments for children (Buhs et al., 2006), research has found that that these events, which often occur after children have entered kindergarten, may not provide sufficient transition support (Early et al., 2001; Pianta et al., 2001).
To reach a wider cross-section of families, some school districts have expanded beyond one-time transition events to establish early kindergarten transition programs, designed to serve as bridges between local communities and their neighborhood schools (Atchison \& Pompelia, 2018; Fonseca, 2017). For example, Somerville Public Schools in Massachusetts initiated a free, four-week program held during the summer in 2008 called the Summer Explore Kindergarten Transition program (Olsen, 2016). The Somerville program developed students' academic and non-academic skills, including learning to write their name and raising their hand to be called on. A similar six-week transition program was established in Georgia, with priority registration given to those families whose children had not attended preschool or Head Start (Fonseca, 2017). The Georgia program was conducted in small classes of 14 students, with a focus on fostering oral language, literacy, and numeracy skills (Fonseca, 2017). In Kentucky, Griebling and Gilbert (2020) evaluated the Me and My School summer transition program for atrisk children. The program ran four to six weeks during the summer and did not use a designated curriculum; teachers instead organized group activities around literacy, math, and movement. The evaluators found reduced anxiety in both students and parents, and an increase in classroom leadership among kindergarteners who participated in the program (Griebling \& Gilbert, 2020). Despite these positive findings, however, scholars observe that such multi-week transition programs are still relatively uncommon across the U.S. (Fonseca, 2017; Griebling \& Gilbert, 2020; La Paro et al., 2003). Numerous early childhood experts have advocated for further exploration of the benefits of these programs on transition outcomes (Bassok et al., 2018; Kang et al., 2017; Meloy et al., 2019).

\section{Purpose of This Study}

To fill this gap in the research, the purpose of this qualitative case study was to investigate parents' perceptions of participating in one multi-week kindergarten transition program, termed Families First (FF), which operates in a large, urban school district located in the Pacific Northwest. In the context of this study, the term "parents" will be used as an inclusive term that also refers to guardians and caretakers that participated in the FF program. Three research questions guided this work: (1) How do parents perceive the experience of participating in the Families First program? (2) How do parents perceive their children's experience of participating in the Families First program? and (3) Which aspects of the Families First program were most helpful to parents and students, and which aspects might benefit from changes in order to better meet the participants' needs? 
This study aimed to fill crucial gaps remaining in the literature. For example, though past research has demonstrated that early childhood transition opportunities generally lead to positive outcomes for children (Kang et al., 2017; Perry \& Dockett, 2011; Rimm-Kaufman \& Pianta, 2000), fewer studies have reported the perspectives of parents as they participate in these programs (Ferguson \& Wood, 2005; Griebling \& Gilbert, 2020; McIntyre et al., 2007). Moreover, specific ways that family involvement impacts kindergarten transition activities continue to be under-investigated (Kang et al., 2017; Rosenkoetter et al., 2009; Wildenger \& McIntyre, 2011). Therefore, findings from this study may illuminate how structured kindergarten transition programs could be improved to serve families who need additional help during the transition to school (Bassok et al., 2018; Kang et al., 2017; Meloy et al., 2019).

\section{Theoretical Framework}

The Families First (FF) program was designed as a twogeneration kindergarten transition program, meaning that both parents and children were considered (Chase-Lansdale \& Brooks-Gunn, 2014). This relatively uncommon framework for kindergarten transition was used because of the emphasis FF places on family involvement in its service model (Bassok et al., 2018). Current evidence suggests that two-generation programs promote increased collaboration between teachers, administrators, parents, and children (Chase-Lansdale \& Brooks-Gunn, 2014; Kaushal, 2014). Utilizing the two-generation model allowed the school district to introduce kindergarten to both parents and students who may not have participated in preschool or other school transition opportunities (Atchison \& Pompelia, 2018; Fonseca, 2017; Griebling \& Gilbert, 2020). Throughout the study, researchers considered the contributions of this model to the outcomes of the kindergarten transition process.

\section{Methods}

To understand the perceptions of parent participants in the FF program, researchers first investigated the structure of FF and how it provided services to students and their families. After this context was investigated, researchers devised a series of semi-structured interview questions to be asked of parents that participated in the program. The steps taken to investigate the research questions are provided in greater detail in the following sections.

\section{Families First Program}

In the summer of 2019 , when this study occurred, the FF kindergarten transition program provided services to students at 13 school sites in a large, urban school district located in the Pacific Northwest. Though all families were encouraged to participate, priority attendance in FF was given to students who had not attended preschool or Head Start; students identified as low income; students identified as emergent bilinguals; students receiving special education services; or students belonging to a historically underserved racial/ethnic category.

The FF program provided services to both children and their parents over the span of three weeks during the summer, with a total of 15 half-day sessions. Students attended the program every day for three hours. Daily sessions began with a soft start so that parents and children could have breakfast together in the cafeteria before the sessions. Sessions for students were structured as a mini-kindergarten day, and included story time, group and table activities, and a focus on transitions between activities and classroom routines. Children also had the opportunity to establish new friendships with peers during recess.

Parent sessions were held twice a week during the children's session and were optional. These sessions varied somewhat from site to site. Most lasted about an hour and included a presentation on a particular topic, a questionand-answer session, and informal time for getting to know other parents. During the sessions, parents met program staff, received information about their child's new school, reviewed kindergarten expectations and routines, explored community resources, discussed the importance of regular attendance, and developed strategies for promoting and supporting learning at home. Translators were available during parent sessions, as was childcare for younger siblings.

At the end of the session, lunch was served in the cafeteria for all parents and children, provided through the summer school lunch program, and many families stayed afterwards to chat and play at the playground. In addition to relationship building, these activities were designed to help students and parents become familiar with classroom and school routines and expectations.

The FF program set three overarching goals for the three-week intervention period before the start of school. These goals were: (a) increase parental involvement in schools, (b) reduce chronic absenteeism in kindergarten, and (c) increase children's readiness for school. These goals aligned with many best practices from the literature for promoting early childhood transitions, including providing continuity to kindergarten readiness routines (Sandall et al., 2005), maximizing involvement among families (Galindo \& Sheldon, 2012), and strengthening the existing bonds within a local community (Hirst et al., 2011). 
Moreover, the organizational structure prioritized family involvement by offering concurrent sessions for both children and their parents. Previous research on FF had revealed the FF program did have a potential significant impact on attendance (Goal b) and that it may not have a significant impact on school readiness (Goal c); however, no research had yet been conducted on the impact of FF on parental involvement (Goal a). This study, therefore, sought to focus on that component of the program's mission statement.

\section{Participants}

To gather the perceptions of parents who participated in the FF program, researchers conducted semi-structured interviews with parents at 5 of the $13 \mathrm{FF}$ sites during the last week of the 2019 program. Family member participants for this study were recruited through purposive convenience sampling using a multi-step process (Patton, 2002). Prospective families were first notified via email by school district administrators that researchers would be conducting a study and that their perceptions of the program would be welcomed. These announcements were also relayed in person to prospective parent participants by local FF site leaders. Researchers were present at the FF sites displaying study signage when parents were both dropping off and picking up their children, allowing parents to participate in an interview on the spot or sign up for a designated time slot, some of which had translators available. No compensation or other benefits were provided upon completion of interviews. In total, 39 parents were interviewed. The participants were distributed across the five schools, with 5 to 11 participants interviewed at each school. Institutional Review Board (IRB) approval was obtained, and all participants provided informed consent.

\section{Positionality}

This study was conducted by university researchers collaborating with the school district through a Researchpractice partnership (RPP). In this particular partnership, school district partners suggest problems of practice they would like help with or program evaluation needs. University researchers, including faculty and doctoral students, designed and conducted studies with the primary goal of answering the districts' research questions. The FF study is part of a series of studies that the RPP has conducted focusing on early learners. The researchers' guiding interest in this study was to help the district understand the impacts of and improve its work with early learners and their families.

\section{Data Collection}

While on location at each FF site, researchers conducted a total of 39 semi-structured interviews lasting between 15 and 20 min each. The interviews were conducted during two time periods: after drop off, when students had left for their sessions, or during lunchtime after the student sessions were complete. Interviews consisted of eight questions, though not all participants answered every question. These questions were designed in line with the literature review and in collaboration with the district to meet their needs and answer the research questions. Sample interview questions included: Tell me a bit about what it was like for you to participate as a parent in the $[F F]$ program. To what extent has it been helpful to meet with school staff? Tell me a bit about what it was like for your child to participate in the [FF] program, and To what extent has it been helpful to meet with other parents? Researchers recorded participant responses to each question by hand and then transferred responses into a word processor.

\section{Data Analysis}

Researchers conducted a series of qualitative coding analyses with the transcripts of the 39 interviews to arrive at substantiated conclusions for this study. During the first phase of analysis, responses from the participants' interviews were coded broadly as positive, neutral, or negative regarding the FF program. Next, data from these interviews were grouped according to the perceived impact of the FF program upon the parent participants or upon their students. Within each of these two response categories, overlapping ideas were aggregated and synthesized to provide a set of common response themes (Saldaña, 2015). A third response category identified ways in which the FF program could be adjusted or improved. Themes derived from each of these coding processes were then analyzed to determine pertinent findings to address each of the three research questions (Saldaña, 2015).

Reliability of results was increased through peer review from multiple researchers reading and coding the interview data to achieve consensual validation (Creswell \& Poth, 2018). Specifically, the two rounds of coding for this study were compared for consistency and double-coded to promote trustworthiness of findings.

\section{Results}

Analysis of interview responses yielded insights regarding each of the three research questions for this study. Results included feedback on the parent sessions and of meeting staff and other families during program events, and parent perceptions of student development in the areas of school 
readiness, self-confidence, and social-emotional behaviors. Lastly, several areas for improvements of the FF program were proposed. Findings pertaining to each of these research categories are presented with select quotes from participants to provide detail and context relevant to each theme.

\section{Parent Perception of Program Impact}

The initial analysis focused on the perception of the overall program, with first-round coding revealing how many parents' responses were positive, negative, or neutral. Table 1 displays the results of parents' impressions of the FF program, divided by question. The percentage of positive responses ranged from 74 to $100 \%$, indicating that parents primarily reacted positively to their FF program experience.

\section{Program Impact on Parents}

Initially, researchers investigated the perceived impact of the program on the parents themselves. The majority (90\%) of parents interviewed attended at least one of the optional parent sessions, and $97 \%$ of parents described the FF program as having had a positive impact on them. Participants revealed that attending these sessions allowed them to access available resources and become more familiar with the school environment. All but one respondent explicitly appreciated that the FF program was held at the school their child would be attending, as this allowed both parents and children to feel more at ease for the start of school. One parent summarized this experience by sharing, "The school is huge and it's easy to get lost, so it's really helpful to have this time to get to know the school before school officially starts."

Parents also described increased understanding of the routines and customs that were specific to each school. One parent described an appreciation for "...learning the processes of the school. It really pulled back the veil and gave transparency for what kids do during the day." Another parent shared, "As a parent, it can be scary to see your child grow up and be independent. I felt that the [parent] meetings were a way to build teacher-parent relationships and learn how to support your child." Additional respondents agreed that the opportunity to ask questions about expectations such as attendance policies or bussing protocols was beneficial.

Parents also described how participating in the FF sessions increased their knowledge of the supports and services that were available for their students. Parents explained that information about resources like the library and schoolbased health clinic helped them feel more confident to seek out what they needed. Participants also referenced takehome resources that provided information about the school. One parent appreciated that the school offered learning games that they could play with their child at home.

The majority of participants (78\%) valued making oneon-one connections with school staff. Parents expressed that meeting their child's teacher helped relieve stress and create a sense of continuity for the start of school. This led multiple participants to feel "known" and "heard," and to feel "calmer" overall. Similarly, attending the parent sessions helped alleviate anxiety about supporting their child's transition to kindergarten. Parents with children who had special needs especially appreciated the ability to meet staff early. One parent explained, "my daughter has an IEP, so [meeting staff] eased anxiety for both me and her. [The teachers] know her now, and I know them. I feel much more comfortable." Another parent was grateful for the opportunity to "explain [their] daughter's weaknesses and needs" to their teacher.

Lastly, nearly $90 \%$ of those interviewed found it helpful to connect with other families through the FF program. Parents reported creating contact lists, scheduling play dates, and seeing familiar faces as some of these benefits. These new community connections also included linguistically diverse parents. For example, at some of the FF sites Spanish-speaking parents were able to connect with each other, while at another site parents made a chat group for Mandarin speakers. The format of the FF program allowed parents to mingle in the cafeteria before and after the sessions as their children ate breakfast and lunch together. One parent summarized their gratitude for these social opportunities by sharing, "It

Table 1 Positive, neutral, and negative perceptions of FF

\begin{tabular}{|c|c|c|c|c|c|}
\hline Interview item ( $n=$ number of responses) & Positive & Neutral & Negative & Not addressed & $\begin{array}{l}\text { Percent of responses } \\
\text { that were positive* }\end{array}$ \\
\hline Helpfulness of FF program for parent $(n=39)$ & 38 & 1 & 0 & 0 & 97 \\
\hline Helpfulness of meeting school staff $(n=23)$ & 18 & 4 & 1 & 16 & 78 \\
\hline Helpfulness of meeting other parents $(n=28)$ & 25 & 3 & 0 & 11 & 89 \\
\hline Program located in assigned school $(n=23)$ & 22 & 1 & 0 & 0 & 96 \\
\hline Change in parent perception of kindergarten $(n=31)$ & 23 & 7 & 1 & 8 & 74 \\
\hline Helpfulness of FF program for child $(n=39)$ & 39 & 0 & 0 & 0 & 100 \\
\hline
\end{tabular}

*Not all parents responded to each question; thus, the percentages listed do not always reflect the sum total of all participants 
was a diverse group and I was able to learn from other parents' experiences."

\section{Parent Perceptions of the Impact on Students}

In addition to providing benefit for parents, all 39 interview participants (100\%) reported that participating in the FF program positively impacted their children. Parents identified several ways that the FF program impacted school readiness in their children, such as building confidence and practicing academic skills. One parent shared that her daughter now knew "the rules, walking in line, lunch line, independence, and where to throw things away." Similarly, other parents reported that their students felt "more confident" as they began to "break out of their shell and not be as shy" when meeting new friends. Another parent explained that these new friendships extended into play dates outside of the school with children in their neighborhood. Multiple respondents shared that their children felt they belonged and were part of those schools now; these were their schools.

Respondents also reported that academic skill-building during the FF program helped their children develop preparedness for learning. For example, one parent shared that their child learned to write their name right side up instead of sideways, and another participant described that the FF activities made their child "excited about writing, reading, and doing homework." A different respondent described how skills carried over at home, where "she's playing pretend school, where she's the teacher and I'm the student, and she sits me down and reads me a book."

Lastly, participants shared observations of how participating in the FF program helped their children acquire new behaviors and attitudes concerning kindergarten. Parents described their students' developing awareness of the importance of getting a good night's sleep, waking up in the morning with enough time to get ready, and working on "not being so grouchy" as their parent helped them get ready. Parents shared that their children "learned to be quiet when the teacher is talking, how to line up," and how to "ask for help" from teachers whenever a problem arose. Another respondent was relieved when their 5-year-old son who was identified with an autism spectrum disorder successfully included himself with peers for the first time in his life. This parent shared that even though their child does not speak much, "I can tell he thinks about his teachers when he goes home. He asked to go see [his teachers] when he was at home. I think he wants to make his teachers proud now."

Families expressed their approval of various aspects of FF. For example, the instruction their students received during the FF program was given as the reason for one parent to decide to keep their child in their neighborhood school rather than applying for a transfer. Other parents cited childcare for younger siblings as an attractive element of the FF program.
These examples highlighted the perception among parents that the FF program contributed to welcoming their families into the school community.

\section{Program Improvements Suggested by Respondents}

Although respondents predominantly spoke about aspects of the FF program that they deemed beneficial, ideas were offered regarding ways that the program could be improved. Suggestions included altering the length of the school day sessions, staffing the program with more individuals who would stay on as teachers during the transition from summer to fall, and increasing the communication with both current and prospective FF attendees.

Some parents expressed a preference for extending the length of the student day. Approximately $15 \%$ of participants suggested that extending the duration could both allow for more academic instruction and remove barriers for working parents to allow their children to participate. One parent explained, "My child would benefit from practicing the whole day routine. I' $m$ not sure if he'll be able to keep going to school after lunch [once kindergarten starts in the fall]!" Another parent added, "The short time per day makes it hard for people going to work when it's only a half day."

On the other hand, $13 \%$ of respondents suggested that the length of parent sessions could be reduced and run more efficiently for working families, with an additional $20 \%$ of respondents citing work or family commitments as reasons why they did not attend more parent sessions. Other parents suggested decreasing the total number of parent sessions in order to allow more working families to participate. One participant shared, "The [parent] sessions were pretty slowpaced... they could be just as effective if they were one time per week. It could save some time for parents that work."

Participants shared a strong desire for teacher continuity so that their children could start the school year with a kindergarten teacher they already knew. Some parents felt that local site leaders were not forthcoming with this information, and that they only found out after asking. Similarly, additional parents observed that various staff members would answer their questions differently, which led to confusion about program operations. The suggestion was made that local site leaders could maintain more consistent messaging, which in turn would allow parents to feel more informed.

Many suggestions were centered around improved communication. For example, $36 \%$ of respondents identified that outreach toward prospective parents should be dramatically improved, as the current marketing of the program was insufficient. Parents suggested that a wider distribution of advertising materials within each school community would result in increased participation, as many families were simply unaware of the opportunity. Additionally, parents 
reported ways that program registration could be improved. One respondent stated that after receiving a flyer in the mail, they enrolled their daughter but did not hear back that she had successfully been registered. Lastly, 33\% of families expressed a desire for stronger day-to-day communication from staff regarding how their children were performing in the program. Some parents wanted more updates about their child's progress, which could have come from more access to the teachers. Taken as a whole, many FF participants thought that communication with parents could be improved both before and during the program.

\section{Discussion}

Several trends emerged regarding how the benefits that parents and children experienced in the FF program might be utilized in other similar kindergarten transition programs. Respondents shared that meeting staff members early during the summer, familiarizing themselves with the layout and routines of their schools, and building stronger social connections with other families were of particular value in helping them best prepare for the start of kindergarten. Similarly, interview participants identified that understanding kindergarten expectations more thoroughly and acquiring tools to support their children at home were helpful, especially for those families who had not previously participated in preschool or other structured school opportunities.

These findings also connected with outcomes from related literature. Forging strong relationships with staff members has been shown to foster kindergarten readiness, with some research suggesting that these connections may yield higher gains in academic competency as compared to other factors, such as student-to-teacher ratios (Howes et al., 2008; Ladd et al., 2000). Moreover, these types of parent-teacher partnerships developed early in the kindergarten experience may also build trust and lead to longer-term family involvement in schools (Goldenberg et al., 2001; Rimm-Kaufman $\&$ Pianta, 2000).

The strongest responses from interview participants centered on the perceived academic, behavioral, and socialemotional benefits for their students. All 39 participants described how their children experienced positive changes during the summer program. In particular, preparation for kindergarten through practice with school routines and behaviors, literacy and numeracy skills, and familiarity with the school building and staff were reported as helpful aspects of the program.

In addition to sharing positive feedback, participants proposed ways that the FF program could better meet the needs of all stakeholders. Improved communication was suggested, both in the outreach to families eligible and with the information provided to families once they had registered.
Research has found that most families want more information from their kindergarten teachers in terms of educational expectations, available learning resources, and recommendations for activities that can be completed at home (Dockett $\&$ Perry, 2007; Wildenger \& McIntyre, 2011).

One concern that emerged from the interviews was that there appeared to be inconsistency in the outreach and communication efforts across sites. For example, though one program coordinator lead and supported the FF program district-wide, differences in the approach to communication at each school site still led to discrepancies in terms of distributing program information. Pianta and colleagues (2001) suggest that one person supervise kindergarten programs at each site to ensure programmatic consistency in the service of equity. This program leader should have direct experience working with families in order to establish rapport, anticipate any needs that may arise, and preempt challenges with careful design (Groark \& McCall, 1996). It may also be important for schools to provide the coordinator with the authority to design and implement a coordinated outreach effort.

Relatedly, some parents expressed a lack of enthusiasm about participating in the adult sessions, with $28 \%$ respondents referring to these events as slow-paced, improperly organized, or lacking in useful content. Participants theorized that the FF sites prioritized planning successful student experiences, and thus may have spent less time organizing the adult informational events. However, most respondents who participated in the sessions stated that they found them helpful, indicating that improved efficiency and preparation could expand these benefits. School districts incorporating parent sessions as a component of kindergarten transition programs may wish to spend equal amounts of time preparing for both offerings. Ensuring that parents have information about best practices for kindergarten may translate into larger school readiness gains for their children (DeCaro \& Worthman, 2011; White, 2020).

\section{Implications for Practice}

The U.S. Department of Education (2015) has observed that children who arrive unprepared for kindergarten often spend their entire elementary school years trying to catch up with learning targets. Scholars have consistently advocated for early intervention to interrupt this cycle of inequity (Bogard \& Takanishi, 2005; McCartney \& Phillips, 2006). However, one-time events may not be adequately preparing families for the start of elementary school (Buhs et al., 2006; Pianta et al., 2001). Kindergarten transition programs like FF may serve a valuable function by bridging the gap in school readiness between those families who participate in preschool or Head Start and those who do not (Atchison \& Pompelia, 2018; Fonseca, 2017; Heckman et al., 2012). Research has 
shown that promoting early childhood initiatives simultaneously benefits all stakeholders, including communities, schools, and families, making them a wise investment for districts (Cunha et al., 2006).

Districts looking to foster stronger outreach towards parents of incoming kindergarteners can start by understanding the needs of each local community more thoroughly (Hammond, 2015; Manigo \& Allison, 2017). Most respondents from this study lamented the lack of advertising for the FF program and asked the district to create additional ways to inform families about the program. School districts could advertise such programs during kindergarten registration and increase publicity through flyers posted at the school site, preschools, local libraries, and community centers. Additionally, information about the FF program could be mailed home in registration packets to qualifying families, including the expectations for parent participation. Literature indicates that families are most empowered when they are provided specific information about their role in the transition to kindergarten (Rimm-Kaufman \& Pianta, 2000; Sandall et al., 2005).

Participants also spoke many different languages and represented a wide variety of cultures. Because family involvement activities are often biased toward the values of white middle-class families (Hornby \& Lafaele, 2011), future transition programs must use the lens of cultural responsiveness to include culturally and linguistically diverse families in meaningful ways (Ansari et al., 2018; Fonseca, 2017; Ladson-Billings, 2014). Participants in this study suggested ways to promote access to program content, including ensuring that translators are present during the parent sessions. In turn, this might encourage increased participation from non-English speaking parents (García-Sánchez et al., 2011). Increasing access to the program and decreasing barriers to participation are both important ways that school districts could increase the cultural responsiveness of future transition programs (Ansari et al., 2018; Galindo \& Sheldon, 2012; Hammond, 2015; Hornby \& Lafaele, 2011).

Similarly, to build strong relationships prior to the start of school, administrators should make efforts to staff the transition program with the same kindergarten teachers who will be returning in the fall. Kraft-Sayre and Pianta (2000) explain that relationships among children, families, and educators are valuable resources that can lead to powerful collaboration when adequately cultivated. Experts maintain that early connections among students, parents, and school staff build a foundation for appropriate support when the need arises (Berns, 2012; Boethel, 2004). A parent suggested moving the FF program adjacent to the beginning of school, rather than occurring during the middle of the summer, to make it easier to coordinate childcare, time off work, and vacations. This move may also make it more appealing for kindergarten teachers with these same responsibilities to staff the program. Programs should not miss opportunities to develop strong bonds among children and their incoming teachers (Kraft-Sayre \& Pianta, 2000; White, 2020).

Lastly, extending the overall time of the program from half-day to full-day sessions may provide students with more opportunities to practice school routines and build attendance stamina (Griebling \& Gilbert, 2020). Literature supports the finding that children are more successful during the transition to kindergarten when their summer experience more closely matches the real environment of their future school days (Dail et al., 2008). Extending the student day and reducing the time commitment for parents may alleviate some of the challenges faced by working parents (Patton $\&$ Wang, 2012). Some participants suggested that offering full-time childcare at each school site might be a way to increase attendance, as it could help families balance work and school responsibilities.

\section{Limitations and Future Directions}

Research for this study investigated the perceptions of parent participants. This was a voluntary study, and not all schools or parents participated. Some locations with a larger number of participants could be overrepresented in the results; it is possible these parents had a more positive experience and those that had a negative experience chose not to participate in the study. Moreover, translators only were available to assist with interviews at certain times. This affected how many responses were gathered, potentially limiting the understanding of the breadth of opinions held by FF participants who needed translators. Demographic information was not collected. Because of the undocumented families in the community, it was deemed likely to decrease participation if too much personal information were to be requested by researchers. This also limited the researchers' ability to follow up with families, and member checking was not completed for this reason.

Finally, this study investigated only the immediate perceptions of parents and guardians. As Patton and Wang (2012) explain, transition is a process rather than a single event. Therefore, investigating parent perceptions regarding their child's kindergarten transition before, during, and after the program had commenced would yield additional insights regarding the needs of families and any potential barriers that exist to their participation in school. Future research may also seek to understand how parents and schools define and perceive readiness, as differences may exist between educators and parents.

Involving parents through parent sessions was one unique feature of the FF program that warrants further exploration on the impact on kindergarten readiness behaviors. More research could investigate how school districts might help parents problem-solve with their children and troubleshoot 
issues during the summer, when the academic stakes are lower. Additional research could address family perceptions longitudinally, at places like reunions and other events planned by the district. Sample inquiries could include: How do families perceive the $F F$ program once their children have finished kindergarten? Further, it may be helpful to measure the impact quantitatively: Does participation in FF measurably increase family involvement during the subsequent kindergarten year? What is the attendance and absentee rate of children in the kindergarten year? Additional research with the program could also explore the impact of the COVID-19 pandemic on kindergarten readiness, and the effects of the FF program on students who delayed kindergarten entry or were otherwise impacted by the pandemic. Additionally, if replicated, gathering demographic information about parent participants and their students could yield further information about the impact of transition programs like FF in specific populations.

\section{Conclusion}

School districts thrive when communities thrive, and communities thrive when the nuanced needs of families are considered, validated, and addressed (Bogard \& Takanishi, 2005; Pianta \& Kraft-Sayre, 2003; Schulting et al., 2005). Participating in the FF program yielded numerous benefits for both parents and their children, including the development of positive school-based routines, a reduction of anxiety regarding what to expect from school, and perceived gains in multiple areas of academics. The opportunity for families to meet their children's prospective teachers was appreciated by parents, especially those parents who had children requiring special education services. These findings are crucial, as the increased social capital created through family involvement has been linked to students' self-perception, intrinsic motivation for learning, attitudes toward school, and their relationships with their teachers (Turney $\&$ Kao, 2009; Walker et al., 2010).

Moving forward, it is imperative that districts and schools engage with families in positive and culturally responsive ways, as research shows that a parent's actions and attitudes at home are crucial in the learning and growth of their child (Bower \& Griffin, 2011; Hilado et al., 2011; Hornby \& Lafaele, 2011). Continued attention and high-quality future research are needed to determine how best to build trust and increase family involvement beginning with students' first contacts with schools.

This study provided ways that administrators and educational leaders can help their staff make positive strides toward improving the lives of families and students. Educators may be able to improve family-school collaboration by both building trust with families and also educating parents about the variety of ways they can be involved, taking advantage of the opportunity presented by the first connections that familiesmake with the school and district at kindergarten transition programs like FF (Goldenberg et al., 2001). Optimizing the beginnings of children's school careers is an important investment society can make to help ensure children's future success (Bogard \& Takanishi, 2005; Cunha et al., 2006; Sylva \& Wiltshire, 1993). As kindergarten transition programs continue to expand across the nation, they hold promise as an effective means that school districts can utilize to reach more student populations and to help them prepare for the start of elementary school.

Acknowledgements No prior work related to this submission is acknowledged.

Author Contributions All authors contributed to the study conception and design. Material preparation, data collection and analysis were performed by CM, BC, SR, NR, EA, and BT. The first draft of the manuscript was written by $\mathrm{CM}$ and all authors commented on previous versions of the manuscript. All authors read and approved the final manuscript.

Funding The authors have no relevant financial or non-financial interests to disclose.

Data Availability All data and materials as well as software applications support published claims and comply with field standards.

Code Availability All codes used to analyze this work are stored in a password-protected computer that are accessible only to contributing researchers and authors of this article.

\section{Declarations}

Conflict of interest The authors have no conflicts of interest to declare that are relevant to the content of this article.

Ethical Approval All procedures performed in studies involving human participants were in accordance with the ethical standards of the institutional and/or national research committee and with the 1964 Helsinki Declaration and its later amendments or comparable ethical standards. The study was approved by the Institutional Review Board on 7/11/2019, \#2019066.

Consent to Participate Informed consent was obtained from all individual participants included in the study.

Consent for Publication No identifying information of any participants was included in this article; thus, consent for publication did not need to be obtained.

\section{References}

Ansari, A., \& Lopez, M. (2015). Preparing low-income Latino children for kindergarten and beyond: How children in Miami's publiclyfunded preschool programs fare. National Research Center on Hispanic Children and Families. Retrieved March 19, 2021 from 
http://www.childtrends.org/wp-content/uploads/2015/09/Hispa nic-Center-MSRP-Brief-FINAL.pdf

Ansari, A., Pivnick, L. K., Gershoff, E. T., Crosnoe, R., \& OrozcoLapray, D. (2018). What do parents want from preschool? Perspectives of low-income Latino/a immigrant families. Early Childhood Research Quarterly, 52, 38-48.

Assel, M. A., Landry, S. H., Swank, P. R., \& Gunnewig, S. (2007). An evaluation of curriculum, setting, and mentoring on the performance of children enrolled in pre-kindergarten. Reading and Writing, 20(5), 463-494.

Atchison, B., \& Pompelia, S. (2018). Transitions and alignment: From preschool to kindergarten. Education Commission of the States. Retrieved March 19, 2021 from https://files.eric.ed.gov/fulltext/ ED588870.pdf

Barbour, A. (2010). Helping children prepare for kindergarten. $P B S$ Parents. Retrieved October 9, 2021 from http://www.pbs.org/ parents/experts/archive/2011/08/helping-children-prepare-for-k. html

Bassok, D., Latham, S., \& Rorem, A. (2016). Is kindergarten the new first grade? AERA Open, 2(1), 2332858415616358.

Bassok, D., Magouirk, P., Markowitz, A. J., \& Player, D. (2018). Are there differences in parents' preferences and search processes across preschool types? Evidence from Louisiana. Early Childhood Research Quarterly, 44, 43-54.

Berns, R. (2012). Child, family, school, community: Socialization and support. Nelson Education.

Boethel, M. (2004). Readiness: Family and community connections with schools. Southwest Educational Development Laboratory.

Bogard, K., \& Takanishi, R. (2005). PK-3: An aligned and coordinated approach to education for children 3 to 8 years old. Social Policy Report, 19(3), 1-24.

Bower, H. A., \& Griffin, D. (2011). Can the Epstein model of parental involvement work in a high-minority, high-poverty elementary school? A case study. Professional School Counseling, 15(2), $77-87$.

Brooks-Gunn, J., Burchinal, M. R., Espinosa, L. M., Gormley, W. T., Ludwig, J., Magnuson, K. A., \& Zaslow, M. J. (2013). Investing in our future: The evidence base on preschool education (Vol. 9). Society for Research in Child Development. Retrieved March 21, 2021 from https://files.eric.ed.gov/fulltext/ED579818.pdf

Buhs, E. S., Ladd, G. W., \& Herald, S. L. (2006). Peer exclusion and victimization: Processes that mediate the relation between peer group rejection and children's classroom engagement and achievement? Journal of Educational Psychology, 98(1), 1-13.

Chase-Lansdale, P. L., \& Brooks-Gunn, J. (2014). Two-generation programs in the twenty-first century. The Future of Children, 24(1), 13-39.

Christakis, E. (2016). The new preschool is crushing kids. The Atlantic. Retrieved March 22, 2021 from https://www.theatlantic.com/ magazine/archive/2016/01/the-new-preschool-is-crushing-kids/ 419139/

Claessens, A., Duncan, G., \& Engel, M. (2009). Kindergarten skills and fifth-grade achievement: Evidence from the ECLS-K. Economics of Education Review, 28(4), 415-427.

Creswell, J. W., \& Poth, C. N. (2018). Qualitative inquiry and research design: Choosing among five approaches (4th ed.). Sage Publications.

Cunha, F., Heckman, J. J., Lochner, L., \& Masterov, D. V. (2006). Interpreting the evidence on life cycle skill formation. National Bureau of Economic Research. Retrieved March 18, 2021 from http://www.nber.org/papers/w11331

Dail, A. R., \& McGee, L. M. (2008). Transition to kindergarten: Reaching back to preschoolers and parents through shared summer school. Childhood Education, 84(5), 305-310.

DeCaro, J. A., \& Worthman, C. M. (2011). Changing family routines at kindergarten entry predict biomarkers of parental stress. International Journal of Behavioral Development, 35(5), 441-448.

Dockett, S., \& Perry, B. (2001). Starting school: Effective transitions. Early Childhood Research and Practice, 3(2), 1-19.

Dockett, S., \& Perry, B. (2007). Transitions to school: Perceptions, expectations and experiences. UNSW Press.

Early, D. M., Pianta, R. C., Taylor, L. C., \& Cox, M. J. (2001). Transition practices: Findings from a national survey of kindergarten teachers. Early Childhood Education Journal, 28(3), 199-206.

Ferguson, C., \& Wood, L. (2005). Easing the transition from pre-K to kindergarten: What schools and families can do to address child readiness. A strategy brief of the national center for family and community connections with schools. Southwest Educational Development Laboratory (SEDL). Retrieved March 13, 2021 from https://files.eric.ed.gov/fulltext/ED486469.pdf

Fonseca, M. (2017). Smoothing out the bumps of transitioning to kindergarten. State technical assistance report. Preschool Development and Expansion Grant Technical Assistance (PDG TA). Retrieved March 20, 2021 from https://files.eric.ed.gov/fulltext/ ED583131.pdf

Galindo, C., \& Sheldon, S. B. (2012). School and home connections and children's kindergarten achievement gains: The mediating role of family involvement. Early Childhood Research Quarterly, 27, 90-103.

García-Sánchez, I. M., Orellana, M. F., \& Hopkins, M. (2011). Facilitating intercultural communication in parent-teacher conferences: Lessons from child translators. Multicultural Perspectives, 13(3), 148-154.

Goldenberg, C., Gallimore, R., Reese, L., \& Garnier, H. (2001). Cause or effect? A longitudinal study of immigrant Latino parents' aspirations and expectations, and their children's school performance. American Educational Research Journal, 38(3), 547-582.

Griebling, S., \& Gilbert, J. (2020). Examining the value of a summer kindergarten transitioning program for children, families, and schools. School Community Journal, 30(1), 191-208.

Groark, C. J., \& McCall, R. B. (1996). Building successful universitycommunity human service agency collaborations. In C. B. Fisher, J. P. Murray, \& I. E. Sigel (Eds.), Applied developmental science: Graduate training for diverse disciplines and educational settings (pp. 237-252). Ablex.

Hammond, Z. (2015). Culturally responsive teaching and the brain. Corwin.

Heckman, J., Pinto, R., \& Savelyev, P. A. (2012). Understanding the mechanisms through which an influential early childhood program boosted adult outcomes. National Bureau of Economic Research.

Hilado, A., Kallemeyn, L., Leow, C., Lundy, M., \& Israel, M. (2011). Supporting child welfare and parent involvement in preschool programs. Early Childhood Education Journal, 39(5), 343-353.

Hilbert, D. D., \& Eis, S. D. (2014). Early intervention for emergent literacy development in a collaborative community pre-kindergarten. Early Childhood Education Journal, 42(2), 105-113.

Hirst, M., Jervis, N., Visagie, K., Sojo, V. \& Cavanagh, S. (2011). Transition to primary school: A review of the literature. Canberra: Commonwealth of Australia. Retrieved March 21, 2021 from http://www.olivephillipskindergarten.com.au/OPK/wp-content/ uploads/2015/11/Transition-to-Primary-School-A-review-oftheliterature.pdf

Hornby, G., \& Lafaele, R. (2011). Barriers to parental involvement in education: An explanatory model. Educational Review, 63(1), $37-52$.

Howes, C., Burchinal, M., Pianta, R., Bryant, D., Early, D., Clifford, R., \& Barbarin, O. (2008). Ready to learn? Children's pre-academic achievement in pre-kindergarten programs. Early Childhood Research Quarterly, 23, 27-50.

Isaacs, J. (2012). Starting school at a disadvantage. The Brookings Institution. Retrieved March 22, 2021 from https://www.brook 
ings.edu/wp-content/uploads/2016/06/0319_school_disadvanta ge_isaacs.pdf

Jeon, H., Langill, C., Peterson, C., Luze, G., Carta, J., \& Atwater, J. (2010). Children's individual experiences in early care and education: Relations with overall classroom quality and children's school readiness. Early Education and Development, 21(6), 912-939.

Kang, J., Horn, E. M., \& Palmer, S. (2017). Influences of family involvement in kindergarten transition activities on children's early school adjustment. Early Childhood Education Journal, 45(6), 789-800.

Kaushal, N. (2014). Intergenerational payoffs of education. The Future of Children, 24(1), 61-78.

Knudsen, E. I., Heckman, J. J., Cameron, J. L., \& Shonkoff, J. P. (2006). Economic, neurobiological, and behavioral perspectives on building America's future workforce. Proceedings of the National Academy of Sciences, 103(27), 10155-10162.

Kraft-Sayre, M. E., \& Pianta, R.C. (2000). Enhancing the transition to kindergarten: Linking children, families and schools. National Center for Early Development and Learning Kindergarten Transition Studies. University of Virginia. Retrieved March 19, 2021 from https://www.pakeys.org/uploadedcontent/docs/Transition\% 20into\%20Formal\%20Schooling/Enhancing\%20the\%20transiti on $\% 20$ to\%20kindergarten\%20Linking\%20children $\% 20$ families\% 20and\%20schools.PDF

La Paro, K. M., Kraft-Sayre, M., \& Pianta, R. C. (2003). Preschool to kindergarten transition activities: Involvement and satisfaction of families and teachers. Journal of Research in Childhood Education, 17(2), 147-158.

Ladd, G. W., Buhs, E. S., \& Seid, M. (2000). Childrens' initial sentiments about kindergarten: Is school liking an antecedent of early classroom participation and achievement? Marrill-Palmer Quarterly, 46(2), 255-279.

Ladson-Billings, G. (2014). Culturally relevant pedagogy 2.0: a.k.a. the remix. Harvard Educational Review, 84(1), 74-84.

LoCasale-Crouch, J., Mashburn, A. J., Downer, J. T., \& Pianta, R. C. (2008). Pre-kindergarten teachers' use of transition practices and children's adjustment to kindergarten. Early Childhood Research Quarterly, 23(1), 124-139.

Manigo, C., \& Allison, R. (2017). Does pre-school education matter? Understanding the lived experiences of parents and their perceptions of preschool education. Teacher Educators Journal, 10, $5-42$.

McCartney, K., \& Phillips, D. (2006). Blackwell handbook of early childhood development. Blackwell Publishing.

McGettigan, I., \& Gray, C. (2012). Perspectives on school readiness in rural Ireland: The experiences of parents and children. International Journal of Early Years Education, 20(1), 15-29.

McIntyre, L. L., Eckert, T. L., Fiese, B. H., DiGennaro, F. D., \& Wildenger, L. D. (2007). Transition to kindergarten: Experiences and involvement. Early Childhood Education Journal, 35(1), 83-88.

Meloy, B., Gardner, M., \& Darling-Hammond, L. (2019). Untangling the evidence on preschool effectiveness: Insights for policymakers. Learning Policy Institute. Retrieved March 19, 2021 from https://learningpolicyinstitute.org/sites/default/files/productfiles/ Untangling_Evidence_Preschool_Effectiveness_REPORT.pdf

Morgan, P., Farkas, G., Hillemeier, M., \& Maczuga, S. (2016). Science achievement gaps begin very early, persist, and are largely explained by modifiable factors. Educational Researcher, 45(1), $18-35$.

Morris, D., Bloodgood, J., \& Perney, J. (2003). Kindergarten predictors of first-and second-grade reading achievement. The Elementary School Journal, 104(2), 93-109.

National Center for Education Statistics. (2020). The Condition of Education 2020. Retrieved March 19, 2021 from https://nces.ed.gov/ fastfacts/display.asp?id=516
Olsen, C. (2016). The summer experience at Somerville public schools. Somerville Public Schools. Retrieved March 22, 2021 from https://somerville.k12.ma.us/blog/summer-experience

Pals, T., \& Jameson, B. (2015). Early childhood programs found to significantly lower likelihood of special education placements in third grade. Retrieved March 23, 2021 from American Education Research Association. http://www.aera.net/Newsroom/NewsR eleasesandStatements/EarlyChildhoodProgramsFoundtoSignif icantlyLowerSpecialEducationPlacementsinThirdGrade/tabid/ 15821/Default.aspx

Patton, M. Q. (2002). Qualitative research and evaluation methods (3rd ed.). Sage Publications.

Patton, C., \& Wang, J. (2012). Ready for success: Creating collaborative and thoughtful transitions into kindergarten. Harvard Family Research Project. Retrieved March 18, 2021 from http://www. hfrp.org/early-childhood-education/publications-resources/readyfor-success-creating-collaborative-and-thoughtful-transitionsinto-kindergarten

Perry, B., \& Dockett, S. (2011). 'How'bout we have a celebration!' Advice from children on starting school. European Early Childhood Education Research Journal, 19(3), 373-386.

Pianta, R. C., \& Cox, M. J. (1999). The transition to kindergarten. A series from the national center for early development and learning. Paul H. Brookes Publishing Company.

Pianta, R., \& Kraft-Sayre, M. (2003). Successful kindergarten transition. Paul Brookes Publishing Co.

Pianta, R. C., Kraft-Sayre, M., Rimm-Kaufman, S., Gercke, N., \& Higgins, T. (2001). Collaboration in building partnerships between families and schools: The national center for early development and Learning's kindergarten transition intervention. Early Childhood Research Quarterly, 16(1), 117-132.

Rimm-Kaufman, S. E., \& Pianta, R. C. (2000). An ecological perspective on the transition to kindergarten: A theoretical framework to guide empirical research. Journal of Applied Developmental Psychology, 21(5), 491-511.

Rosenkoetter, S., Schroeder, C., Rous, B., Hains, A., Shaw, J., \& MacCormick, K. (2009). A review of research in early childhood transition: Child and family studies. Technical report \#5. University of Kentucky, Human Development Institute, National Early Childhood Transition Center. Retrieved March 21, 2021 from http:// www.Ihdi.uky.edu/nectc/

Saldaña, J. (2015). The coding manual for qualitative researchers. Sage.

Sandall, S., Hemmeter M. L., Smith B. J., McLean M. E. (2005). DEC recommended practices: A comprehensive guide for practical application in early intervention/early childhood special education. Division for Early Childhood (DEC)

Schulting, A. B., Malone, P. S., \& Dodge, K. A. (2005). The effect of school-based kindergarten transition policies and practices on child academic outcomes. Developmental Psychology, 41, $860-871$.

Sylva, K., \& Wiltshire, J. (1993). The impact of early learning on children's later development a review prepared for the RSA inquiry 'start right.' European Early Childhood Education Research Journal, 1(1), 17-40.

Turney, K., \& Kao, G. (2009). Barriers to school involvement: Are immigrant parents disadvantaged? The Journal of Educational Research, 102(4), 257-271.

U.S. Department of Education. (2015). A matter of equity: Preschool in America. Retrieved March 22, 2021 from https://www2.ed.gov/ documents/early-learning/matter-equity-preschool-america.pdf

Walker, J. M., Shenker, S. S., \& Hoover-Dempsey, K. V. (2010). Why do parents become involved in their children's education? Implications for school counselors. Professional School Counseling, 14(1), 27-41. 
White, K. M. (2020). Building strong teacher-child relationships in today's kindergarten classroom: Focusing on opportunities versus obstacles. Journal of Early Childhood Research, 18(3), 275-286.

Wildenger, L. K., \& McIntyre, L. L. (2011). Family concerns and involvement during kindergarten transition. Journal of Child and Family Studies, 20, 387-396.
Publisher's Note Springer Nature remains neutral with regard to jurisdictional claims in published maps and institutional affiliations. 